\title{
Effect of Virtual Reality compared to Guided Visualization on Arteriovenous Fistula Cannulation pain and pain anxiety among hemodialysis children
}

\author{
Basma Mahmoud Dawood ${ }^{1}$,Eslam Mohammed Gado ${ }^{2}$, Shimaa Ramadan Ahmed $^{3}$ \& Samya Mohamed Hegazy ${ }^{4}$ \\ 1. Lecturer of Pediatric Nursing, Faculty of Nursing, Tanta University, Egypt. \\ 2. Lecturer of Psychiatric and Mental Health Nursing, Faculty of Nursing, Tanta University Egypt. \\ 3. PHD of Pediatric Nursing, Training and Continuing Education Coordinator for Tanta University Hospitals Egypt. \\ 4. Lecturer of Pediatric Nursing, Faculty of Nursing, Tanta University Egypt.
}

\begin{abstract}
Background: Children undergoing treatment with hemodialysis are exposed frequently to pain and anxiety which are caused by the insertion of large-gauge needles into an arteriovenous fistula. Non pharmacological pain management methods such as virtual reality and guided visualization are used to manage pain and pain related anxiety. Aim: to evaluate the effect of virtual reality compared to guided visualization on arteriovenous fistula cannulation pain and pain anxiety among hemodialysis children. Setting: the study was carried out at the Tanta Main University Hospital, Pediatric Medical Department, Dialysis Unit, Tanta City, Egypt. Sample: a convenience sampling of thirty children undergoing hemodialysis with arteriovenous fistula were included from the previously mentioned setting. Tools: there were three tools used: Tool I: Structured interview schedule, consisting of three components: sociodemographic characteristics of the children, data about the caregiver of the child and data related to the disease and fistula. Tool II: Wong-Baker faces pain rating scale for children. Tool III: Pain Anxiety Symptom Scale Short Form which was developed by McCracken (2002). Results: 53.33\% and 33.33\% of the studied children had moderate and severe pain anxiety symptoms pre-intervention respectively while $73.33 \%$ and 46.67\% of them had mild pain anxiety symptoms during application of virtual reality and guided visualization respectively. Conclusion: visual reality was the preferred method which given the greater relief of pain and pain anxiety than guided visualization. Recommendations: visual reality should be used and disseminated to other hemodialysis centers as a strategy to reduce pain and pain anxiety among those children undergoing hemodialysis.
\end{abstract}

Keywords: Effect, Arteriovenous Fistula, Virtual Reality, Children, Guided Visualization, Hemodialysis, Pain \& Pain anxiety.

\section{Introduction:}

Chronic kidney disease (CKD) is a progressive, irreversible renal disease in which the ability of the body to maintain the balance of metabolism, fluid and electrolytes fails (Ibrahim \& Abdelgawad 2017). The most common causes in children under the age of 5 are congenital malformations such as congenital aplastic, hypoplastic, dysplastic kidney and obstructive uropathy. In the age group of 5 to 15 years, inherited and acquired kidney disorders are common causes of (CKD) (Basu et al 2011 \& Masalskienè et al 2021). In the Arab world, the prevalence of chronic renal failure (CRF) in children is high. The reported prevalence of CRF in Saudi Arabia is 80 to 120 per million population (pmp) and 225 pmp in Egypt. It is reported in Europe to be 283 and 957 pmp in the United States (Ibrahim \& Abdelgawad 2017).

The child needs renal replacement therapies, such as peritoneal dialysis, hemodialysis and kidney transpla ntation, when the glomerular filtration rate is below $15 \mathrm{ml} / \mathrm{min} / 1.73 \mathrm{~m} 2$. This stage can be referred to as "end-stage kidney disease (ESKD)"( Bingamin \&

Lappin 2020, Vaidya \& Aeddula 2020). Nearly two million patients worldwide are dialysis-dependent, with around 90\% receiving hemodialysis three days a week (Yalda et al 2020).

Hemodialysis for ESKD patients is the most commonly used renal replacement treatment. It is a medical procedure that removes excess and extra water out of the blood using a machine with a special filter. Appropriate hemodialysis (HD) treatment needs well-functioning vascular access that lessens patient's morbidity. Arteriovenous fistula (AVF) is the preferred form of permanent vascular access, that requiring a smaller number of actions, substantially less infectious complications and better dialysis quality (Yalda et al 2020 \& Onder et al 2020).

Stress, anxiety and pain induced by the insertion of large-gauge needles into an AVF are repeated symptoms and problems of the children experiencing hemodialysis. On average, there are more than 20 AVF punctures per month for a child undergoing routine hemodialysis and he or she will have it during his or her lifetime (Celik et al 2011 \&Moosazadeh et al 2020). The frequent hemodialysis pain caused by fistula cannulation can lead to anxiety, depression, and decreased patients' quality of life. Efficient pain control will lead these patients to approve 
hemodialysis, and their quality of life will be enhanced. (Hassan et al 2013).

Nurses play an important role in improving quality, adequacy and helping the patient to understand his or her condition, recognize his or her treatment goals and plan for decisions that will need to be made as the condition progresses toward hemodialysis over time, and explain the process to family members and answer their questions to protect their children from complications of hemodialysis (Abdalmajed 2017).

The priority in nursing and one of the essential aspects of professional nursing is pain assessment and management (Davtalab et al 2016). Nurses should also be conscious of the physical and mental effects of this pain and find some appropriate ways to control it (Gong et al 2014). There are many ways of minimizing discomfort and anxiety caused by cannula insertion, which may reinforce the acceptance of the treatment by children and therefore improve their quality of life(Celik et al 2011 , Tomasello et al 2018). Pain-reducing methods can be grouped basically, into two categories; non pharmacological and pharmacological (Alalo et al 2016). Although pharmacological interventions can be used, non-pharmacological techniques that depend on distraction as guided visualization and virtual reality that are simple and effective techniques that direct children's attention away from painful and anxious stimuli (Donna \& Ran 2012).

Guided imagery is a relaxing technique that includes sitting or lying peacefully and imagining a favorite, relaxing place like a beach and meadow. It uses imagination to alter the thoughts of the patient by working on his or her senses (sound, vision, smell, taste, touch, movement) that's almost like daydreaming. A patient's pain, stress, anxiety and other symptoms associated with his or her condition may be relieved by creating images in his or her brain (CHOC 2021).

Virtual Reality (VR) refers to a computer-generated experience in which a child can use electronic equipment, such as special goggles with a screen or gloves equipped with sensors, to interact in an artificial three-dimensional world. The child is able to have a realistic experience in this simulated artificial world which can simultaneously provide complete distraction to patients Guided visualization and virtual reality therapies have been proven to be effective in reducing patients' anxiety, pain and widely accepted by both the patients and also physicians (Michell 2021, Wong et al 2019 \& Othman et al 2013).
Significance of the problem:

Children and adolescents with end stage renal diseases suffer from impaired quality of life especially those undergoing hemodialysis (HD) which mean that they need to face an average of ten punctures every month with its associated pain and anxiety, which may affect their health and capacity to function. The long-lasting need for continuation of hemodialysis and the negative effects of the associated pain and anxiety on the children and their family make them a priority of care for HD children (Obiago et al 2018 \& Alhani, 2010). Pain caused by AVF puncture during hemodialysis is a significant cause of concern for both children and nurses because of the diameter and length of needles. Pain and related anxiety assessment and management should be considered as a vital element of nursing care that nurses should perform alongside their roles for those delicate children. Consequently, nurses should be conscious of the physical and mental symptoms of this pain and its related anxiety and apply efficient and updated techniques for managing them (Kaspar et al 2016, Bonnie \& Stevens 2012). The current study aimed to evaluate the effect of virtual reality compared to guided visualization on a reduction of arteriovenous fistula cannulation pain and its related anxiety among hemodialysis children.

Aim of this study:

The present study aimed to evaluate the effect of virtual reality compared to guided visualization on arteriovenous fistula cannulation pain and pain anxiety among hemodialysis children

Research Hypothesis:

virtual reality technique is expected to reduce arteriovenous fistula canulation pain and pain related anxiety more effectively than guided visualization among hemodialysis children.

\section{Subjects and Method \\ Research Design:}

The present study used a quasi-experimental research design.

Setting:

The study was carried out at the Tanta Main University Hospital, Pediatric Medical Department, Dialysis Unit which consisted of 2 rooms and outdoor waiting chairs for the care givers of the children. The large room contained seven automatic chairs with dialysis machine beside each chair. The other room contained three automatic chairs with dialysis machine beside each chair.

Subjects:

A convenience sampling of thirty children undergoing hemodialysis with arteriovenous fistula was collected from the above previously mentioned 
setting. The size of sample was based on the following parameters confidence level error level 5\% type I error 0.05 and power of test $95 \%$. The sample size was calculated using Steven Thimpson's equation.

$$
n=\frac{N \times P(1-P)}{\left(N-1 \times\left(d^{2} / z^{2}\right)+P(1-P)\right.}
$$

$\mathrm{N}=$ total society size $(50)$

$\mathrm{D}=$ error percentage $(0.05)$

$\mathrm{Z}=$ the correspond stander class of significant $95 \%$ (1.69)

$\mathrm{P}=$ percentage of availability of the objectivity $=(0.1)$

$\mathrm{n}=$ sample size $(30)$

Inclusion criteria:

- Age from 6-16 years.

- Both sexes.

- Children who had functioning arteriovenous fistula that actually used in hemodialysis.

- Children who are conscious of time, place, and individuals at the time of data collection

Exclusion criteria:

- Children who used analgesics or local anesthesia 24 hours before hemodialysis.

- Children who required more than one attempt to puncture the fistula.

- Children who had history of mental illness

Tools of data collection:

In the current study, three tools were used as the following:

Tool I: Structured interview schedule:

It was created by a researcher following a review of the literatures (Yalda et al 2020 \& Onder et al 2020). It composed of three parts. Part 1 : sociodemographic characteristics of the children which consisted of their age, sex, residence and level of education. Part 2: Data about the child's caregiver, which included; age, gender, educational level and occupation. Part 3: Data related to the disease and fistula which included; the duration of disease, the duration of hemodialysis, frequency of hemodialysis per week, duration of each hemodialysis session in hours, site, type and duration of their arteriovenous fistula.

Tool II: Wong-Baker faces pain rating scale for children:

Wong-Baker faces pain-rating scale Wong (1988) used to assess the children's pain intensity during arteriovenous fistula cannulation before application of any of the studied interventions, after applying guided visualization and after applying virtual reality eyeglasses. The scale consisted of six drawn faces expressing various degrees of pain, severity ranged from "not hurt" to "hurts worst". In this method the scoring system of Wong-Baker faces pain rating
Scale was as following no pain 0, mild pain 1-3, moderate pain 4-6 and severe pain 7-10.

Tool III: Pain Anxiety Symptom Scale Short Form The scale was developed by ( McCracken 2002). It included 20 items related to the child's pain anxiety symptoms, each item scored from 0 to 5 on a 5 -point scale as the following: never pain anxiety symptoms (0), almost never (1), sometimes (2), often a problem (3), almost (4), and always pain anxiety symptoms (5). Also, it included four subscales which reflected the aspects of cognitive anxiety (items 1 to 5 e.g., It's hard for me to think about something other than pain during painful episodes) avoidance or escape behaviors (items 6 to 10 e.g., As soon as I feel pain coming, I will stop any action.), fear (items 11 to 15 e.g., when I fear that something bad will happen,) and physiological anxiety (items 16 to 20 e.g., After periods of pain, I find it hard to calm my body down). The total score of Pain Anxiety Symptom Scale severity was categorized as following; mild (0-34), moderate (35-67), and severe (68-100). The higher scores Indicates higher levels of pain related anxiety.

\section{Method}

The study was conducted through the following steps:

The process of administration:

An official permission was obtained on September 2020 to carry out the study from the responsible authorities of the dialysis unit of Pediatric Medical department at Tanta Main University Hospital to obtain their approval and cooperation to conduct the study.

\section{Ethical and legal considerations:}

The study's nature not causing any harm or pain to the entire subject. Oral consents were taken from parents and their children to participate in the study after illustrating the aim of the study. They have the right to walk away from the study at any time. Children and their parents were informed about the confidentiality of their information and it was used only for the purpose of the study.

Tools Development:

Tools used for data collection were three; Tool I: structured interview schedule: It was developed by the researcher and consist of three parts. Tool II: Wong-Baker faces pain rating scale that was adopted from Wong (1988). Tool III: Pain Anxiety Symptom Scale Short Form developed by McCracken (2002) that consisted of 20 items relating to the child's pain anxiety symptoms which composed of the following subscales: cognitive, escape or avoidance, fear, and physiological anxiety.

Content validity: 
A jury of five experts in the fields of pediatric nursing, psychiatric nursing and pediatric medicine was provided with the first tool to verify the validity of the content, clarification, significance, completeness, comprehension, applicability and simplicity of application. The index of content validity was 98 percent

\section{Reliability:}

of developed tools was tested through internal consistency. The value of Cronbach's alpha coefficient was 0.90

\section{A Pilot study:}

A pilot study was performed on three children (10\%) of the sample to test clarity, visibility and applicability of the study tools and the needed changes were made. Those children were excluded from total sample of the study.

\section{The study Phases:}

The study was carried out through three phases:

1. Assessment phase: It was done by the researchers for entire studied subjects to collect the baseline data, and to assess children who met inclusive and exclusive criteria. The researchers met the nurses and doctors who were working in the previously described setting to explain the study's purpose to them. Also, the children and their parents were interviewed by the researchers after obtaining oral consent from them.

2. Implementation phase: The study interventions were conducted through three sessions:

The first session:

The researcher was available three days a week attended from 9:00 a.m.until 12:00 p.m. to collect the data. The parents were asked about sociodemographic data, the children's disease and fistula related data (tool I). This step took about 10 minutes. Then, the child was lying on the bed and the cannulation pain's score was marked by researcher using Wong Baker faces pain rating scale during fistula puncture (arteriovenous cannulation) before applying the study interventions to fulfill tool II. After that, the researcher asks the child about 20 items relating to the child's pain anxiety symptoms including cognitive, escape or avoidance, fear and physiological anxiety. Then the researcher gave a score to each item using a numerical rating scale to cover tool III which took about 15-20 minutes.

\section{The second session:}

It was the first intervention session, the researcher prepares the child for the virtual reality technique; 20 minutes before hemodialysis, the child lay on the bed and wore virtual reality eyeglasses, the eyeglasses were placed on the child's head, the child watched 3 D VR kids' cartoons or videos to distract his/her attention during needle insertion. The video was displayed through a smart phone inserted inside the virtual reality headset. The fistula was cannulated while the child watching the video, then the researcher recorded the score of pain using the Wong - Baker faces pain rating scale and assessed the pain anxiety level using pain anxiety symptoms scale after applying the virtual reality eyeglasses.

\section{The third session:}

It was the second intervention session. In which the researchers provided a quiet environment such as a room with low light and away from noises and prepared child for the guided visualization technique by asking the child to be in the supine position 20 minutes before the hemodialysis, closed eyes, took deep breath through the nose and slowly exhaled it from the mouth, complete relaxation of the body for two minutes. The researcher asked the child to perform mental imagery for 20 minutes before needles insertion into arteriovenous fistula through imagination of a beautiful place or a popular topic or funny situation for the child and focus on it. The fistula was inserted while the child describing what was imagined in his mind. Then, the researcher recorded the score of pain using the Wong - Baker faces pain rating scale and the pain related anxiety using Pain Anxiety Symptom Scale after applying the guided visualization.

\section{Evaluation phase:}

It was done for children three times before applying intervention, after applying virtual reality eye glasses, and after applying guided visualization. The data was collected over a period of time three months from September 2020 until December 2020 


\section{Results:}

Table (1): Percentage distribution of the studied children according to their socio-demographic characteristics

\begin{tabular}{|c|c|c|}
\hline \multirow{2}{*}{ Characteristics of the studied children } & \multicolumn{2}{|c|}{$\mathbf{n}=\mathbf{3 0}$} \\
\hline & $\%$ & No. \\
\hline $\begin{array}{l}\text { Age (Years) } \\
6- \\
9- \\
12-\geq 16\end{array}$ & $\begin{array}{c}5 \\
7 \\
18 \\
\end{array}$ & $\begin{array}{l}16.67 \\
23.33 \\
60.00\end{array}$ \\
\hline $\begin{array}{l}\text { Range } \\
\text { Mean } \pm \text { SD }\end{array}$ & \multicolumn{2}{|c|}{$\begin{array}{c}6-16 \\
11.933 \pm 2.753\end{array}$} \\
\hline $\begin{array}{l}\text { Sex } \\
\text { Male } \\
\text { Female }\end{array}$ & $\begin{array}{l}11 \\
19\end{array}$ & $\begin{array}{l}36.67 \\
63.33\end{array}$ \\
\hline $\begin{array}{l}\text { Residence } \\
\text { Urban } \\
\text { Rural }\end{array}$ & $\begin{array}{l}15 \\
15\end{array}$ & $\begin{array}{l}50.00 \\
50.00\end{array}$ \\
\hline $\begin{array}{l}\text { Educational Level } \\
\text { Primary school } \\
\text { Preparatory school } \\
\text { Secondary school }\end{array}$ & $\begin{array}{c}19 \\
6 \\
5\end{array}$ & $\begin{array}{l}63.33 \\
20.00 \\
16.67\end{array}$ \\
\hline
\end{tabular}

Table (2): Percentage distribution of caregivers of the studied children according to their sociodemographic characteristics

\begin{tabular}{|l|c|c|}
\hline \multirow{2}{*}{ Characteristics of children's caregiver } & \multicolumn{2}{|c|}{ No30 } \\
\cline { 2 - 3 } Age of care giver (Years) & \multicolumn{2}{|c|}{$\%$} \\
$20-$ & 14 & $27-54$ \\
$40-\geq 60$ & 16 & $39.333 \pm 6.546$ \\
\hline Range & \multicolumn{2}{|c|}{} \\
Mean \pm SD & 10 & 53.3 \\
\hline Gender & 20 & 33.33 \\
Male & \multicolumn{2}{|c|}{} \\
Female & 13 & 66.67 \\
\hline Education of care giver & 6 & 43.33 \\
Illiterate & 1 & 20.00 \\
Read and write & 7 & 3.33 \\
Preparatory school & 3 & 10.00 \\
Diploma education & & \\
University education & 5 & 16.67 \\
\hline Occupation & 25 & \\
Working & & \\
Not working & & \\
\hline
\end{tabular}


Table (3): Percentage distribution of the studied children according to their Disease and arteriovenous fistula characteristics

\begin{tabular}{|c|c|c|}
\hline \multirow{2}{*}{ Data related to children's disease and fistula } & \multicolumn{2}{|c|}{$n=30$} \\
\hline & No & $\%$ \\
\hline $\begin{array}{l}\text { Duration of disease before starting } \\
\text { hemodialysis /years } \\
1- \\
5- \\
10-\end{array}$ & $\begin{array}{c}14 \\
12 \\
4\end{array}$ & $\begin{array}{l}46.66 \\
40.00 \\
13.33\end{array}$ \\
\hline $\begin{array}{l}\text { Range } \\
\text { Mean } \pm \text { SD }\end{array}$ & & \\
\hline $\begin{array}{l}\text { Duration of hemodialysis/years } \\
\geq 1-5 \\
6-\geq 10\end{array}$ & $\begin{array}{c}27 \\
3\end{array}$ & $\begin{array}{l}90.00 \\
10.00\end{array}$ \\
\hline $\begin{array}{l}\text { Range } \\
\text { Mean } \pm \text { SD }\end{array}$ & & \\
\hline $\begin{array}{l}\text { Number of dialysis session /week: } \\
\text { Range } \\
\text { Mean } \pm \text { SD }\end{array}$ & & \\
\hline $\begin{array}{l}\text { Duration of dialysis session /hours: } \\
3 \text { hours/session } \\
4 \text { hours/session }\end{array}$ & $\begin{array}{l}13 \\
17\end{array}$ & $\begin{array}{l}43.33 \\
56.66\end{array}$ \\
\hline $\begin{array}{l}\text { Fistula site: } \\
\text { Right arm } \\
\text { Left arm }\end{array}$ & $\begin{array}{l}10 \\
20\end{array}$ & $\begin{array}{l}33.33 \\
66.67\end{array}$ \\
\hline $\begin{array}{l}\text { Fistula type: } \\
\text { Radio cephalic } \\
\text { Brachiocephalic } \\
\text { Brachiobasillic }\end{array}$ & $\begin{array}{c}1 \\
25 \\
4\end{array}$ & $\begin{array}{l}3.33 \\
83.33 \\
13.33\end{array}$ \\
\hline $\begin{array}{l}\text { Duration of fistula(years) } \\
\text { Range } \\
\text { Mean } \pm \text { SD }\end{array}$ & & \\
\hline
\end{tabular}

Table (4) Percentage distribution of the studied children's total pain scores during arteriovenous fistula canulation pre and post interventions: virtual reality and guided visualization.

\begin{tabular}{|c|c|c|c|c|c|c|c|c|c|c|}
\hline \multirow[t]{2}{*}{ Total pain score } & \multicolumn{2}{|c|}{ Pre intervention } & \multicolumn{2}{|c|}{$\begin{array}{c}\text { Post } \\
\text { Virtual } \\
\text { Reality }\end{array}$} & \multicolumn{2}{|c|}{$\begin{array}{c}\text { Post Guided } \\
\text { Visualization }\end{array}$} & \multirow[t]{2}{*}{ Chi-Square } & \multirow[t]{2}{*}{ P\&R } & \multirow[t]{2}{*}{ P\&V } & \multirow[t]{2}{*}{$\mathbf{R} \& \mathbf{V}$} \\
\hline & $\mathbf{N}$ & $\%$ & $\mathbf{N}$ & $\%$ & $\mathbf{N}$ & $\%$ & & & & \\
\hline No pain & 0 & 0.00 & 1 & 3.33 & 0 & 0.00 & $\mathrm{X}^{2}$ & 25.227 & 7.646 & 8.073 \\
\hline Mild pain & 4 & 13.33 & 21 & 70.00 & 13 & 43.33 & P-value & $<0.001 *$ & $0.022 *$ & $0.045^{*}$ \\
\hline Moderate pain & 16 & 53.33 & 8 & 26.67 & 13 & 43.33 & & & & \\
\hline Severe pain & 10 & 33.33 & 0 & 0.00 & 4 & 13.33 & & & & \\
\hline
\end{tabular}

*Statistically significant difference at $(P<0.05)$ 
Table (5): Distribution of the studied children according to their mean score of Pain Anxiety level pre and post interventions: virtual reality and guided visualization

\begin{tabular}{|c|c|c|c|c|c|c|c|c|c|c|c|c|}
\hline \multirow{5}{*}{$\begin{array}{l}\text { Subscale } \\
\text { items } \\
\\
\text { Cognitive } \\
\text { (Items 1- } \\
\text { 5) }\end{array}$} & \multirow{3}{*}{$\begin{array}{c}\text { Time } \\
\text { pre-intervention }\end{array}$} & \multirow{2}{*}{\multicolumn{3}{|c|}{ Range }} & \multirow{2}{*}{\multicolumn{3}{|c|}{ Mean \pm SD }} & \multirow{3}{*}{$\begin{array}{l}\text { CO } \\
\text { MP. } \\
\text { P-R }\end{array}$} & \multicolumn{2}{|c|}{ Differences } & \multicolumn{2}{|c|}{ Paired Test } \\
\hline & & & & & & & & & \multirow{2}{*}{$\begin{array}{l}\text { Mean } \\
7.267 \\
\end{array}$} & \multirow{2}{*}{$\begin{array}{c}\text { SD } \\
6.528 \\
\end{array}$} & \multirow{2}{*}{$\begin{array}{c}\mathbf{t} \\
6.097 \\
\end{array}$} & \multirow{2}{*}{$\begin{array}{l}\text { P-value } \\
<0.001^{*}\end{array}$} \\
\hline & & 5 & - & 25 & 16.600 & \pm & 6.896 & & & & & \\
\hline & $\begin{array}{ll}\text { Post } & \text { Virtual } \\
\text { Reality } & \\
\end{array}$ & 5 & - & 15 & 9.333 & \pm & 2.893 & P-V & 4.333 & 4.830 & 4.914 & $<0.001 *$ \\
\hline & $\begin{array}{l}\text { Post Guided } \\
\text { Visualization }\end{array}$ & 5 & - & 25 & 12.267 & \pm & 6.297 & $\mathbf{R}-\mathbf{V}$ & -2.933 & 5.735 & $2 . \overline{8} 01$ & $0.009 *$ \\
\hline \multirow{3}{*}{$\begin{array}{l}\text { Escape/ } \\
\text { Avoidanc } \\
\text { e } \\
\text { (Items 6- } \\
\text { 10) }\end{array}$} & pre-intervention & 6 & - & 23 & 13.933 & \pm & 4.913 & P-R & 6.400 & 4.182 & 8.382 & $<0.001^{*}$ \\
\hline & $\begin{array}{ll}\text { Post } & \text { Virtual } \\
\text { Reality } & \\
\end{array}$ & 5 & - & 13 & 7.533 & \pm & 2.501 & P-V & 3.500 & 3.776 & 5.077 & $<0.001^{*}$ \\
\hline & $\begin{array}{l}\text { Post Guided } \\
\text { Visualization }\end{array}$ & 5 & - & 19 & 10.433 & \pm & 3.830 & $\mathbf{R}-\mathbf{V}$ & -2.900 & 3.478 & $4 . \overline{568}$ & $<0.001 *$ \\
\hline \multirow{3}{*}{$\begin{array}{l}\text { Fear } \\
(\text { Items } \\
\text { 11-15) }\end{array}$} & pre-intervention & 6 & - & 23 & 14.767 & \pm & 5.399 & P-R & 6.667 & 4.852 & 7.526 & $<0.001 *$ \\
\hline & $\begin{array}{ll}\text { Post } & \text { Virtual } \\
\text { Reality } & \\
\end{array}$ & 5 & - & 13 & 8.100 & \pm & 2.708 & P-V & 3.900 & 4.421 & 4.832 & $<0.001 *$ \\
\hline & $\begin{array}{l}\text { Post Guided } \\
\text { Visualization }\end{array}$ & 5 & - & 24 & 10.867 & \pm & 5.367 & R-V & -2.767 & 4.754 & $3 . \overline{188}$ & $0.003 *$ \\
\hline \multirow{3}{*}{$\begin{array}{l}\text { Physiolog } \\
\text { ical } \\
\text { Anxiety } \\
\text { (Items } \\
\text { 16-20) } \\
\end{array}$} & pre-intervention & 6 & - & 20 & 12.600 & \pm & 4.166 & P-R & 6.167 & 3.455 & 9.776 & $<0.001 *$ \\
\hline & $\begin{array}{ll}\text { Post } & \text { Virtual } \\
\text { Reality } & \\
\end{array}$ & 3 & - & 13 & 6.433 & \pm & 2.254 & P-V & 4.433 & 3.794 & 6.401 & $<0.001^{*}$ \\
\hline & $\begin{array}{l}\text { Post Guided } \\
\text { Visualization }\end{array}$ & 4 & - & 15 & 8.167 & \pm & 3.302 & $\mathbf{R}-\mathbf{V}$ & -1.733 & 2.947 & $3 . \overline{2} 21$ & $0.003 *$ \\
\hline \multirow{3}{*}{$\begin{array}{l}\text { Total } \\
\text { score }\end{array}$} & pre-intervention & 28 & - & 86 & 57.900 & \pm & 18.387 & P-R & 26.500 & 15.883 & 9.139 & $<0.001^{*}$ \\
\hline & $\begin{array}{ll}\text { Post } & \text { Virtual } \\
\text { Reality } & \\
\end{array}$ & 19 & - & 49 & 31.400 & \pm & 7.994 & P-V & 16.167 & 13.832 & 6.402 & $<0.001^{*}$ \\
\hline & $\begin{array}{l}\text { Post Guided } \\
\text { Visualization }\end{array}$ & 20 & - & 78 & 41.733 & \pm & 16.856 & R-V & -10.333 & 15.264 & $3 . \overline{708}$ & $0.001 *$ \\
\hline
\end{tabular}

*Statistically significant difference at $(P<0.05)$

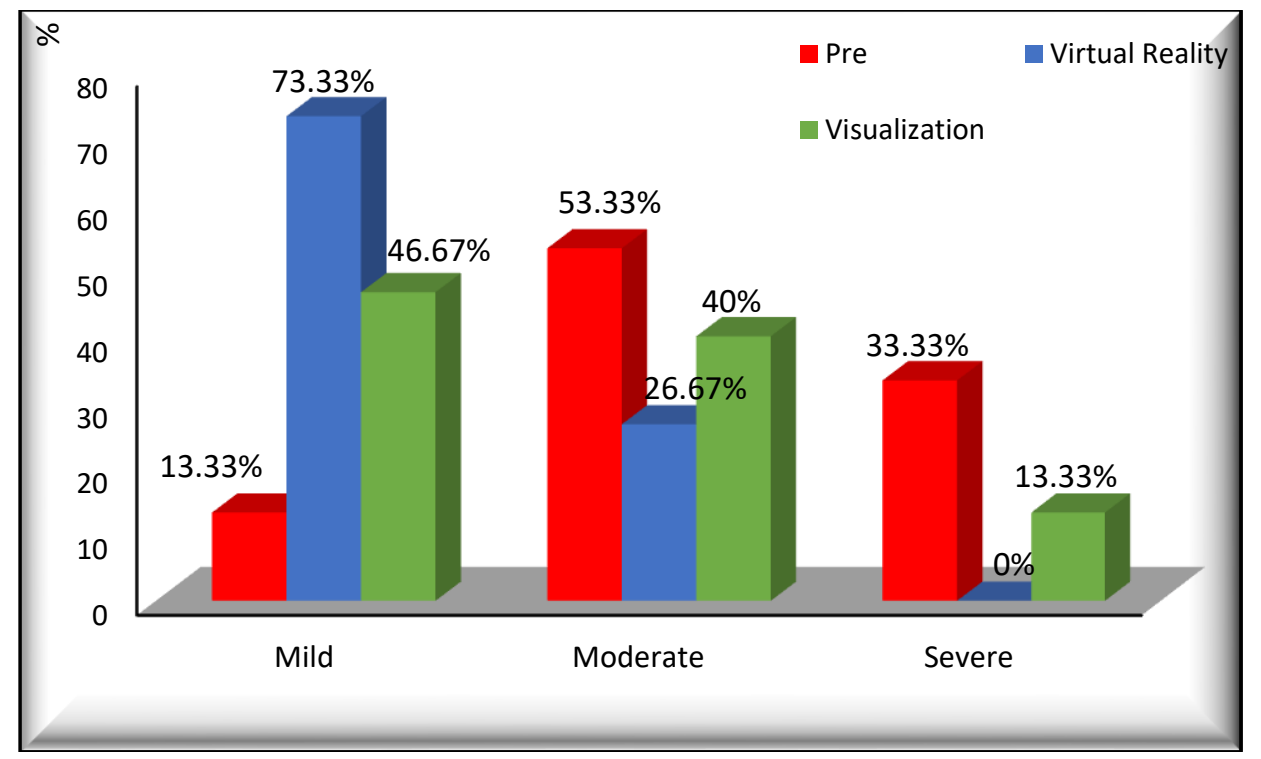

Figure (1): Percentage distribution of the studied children's total scores of Pain Anxiety levels pre and post interventions: virtual reality and guided visualization. 
Table (6): Relation between the studied children's total pain score and means scores of Pain Anxiety levels pre and post interventions

\begin{tabular}{|c|c|c|c|c|c|c|c|}
\hline \multirow{2}{*}{\multicolumn{2}{|c|}{ Total pain scores }} & \multicolumn{4}{|c|}{ Total mean scores of Pain Anxiety } & \multicolumn{2}{|c|}{ ANOVA } \\
\hline & & $\mathbf{N}$ & Mean & \pm & SD & $\mathbf{F}$ & P-value \\
\hline \multirow{3}{*}{$\begin{array}{c}\text { Pre- } \\
\text { intervention }\end{array}$} & Mild pain & 4 & 62.000 & \pm & 15.449 & \multirow{3}{*}{3.659} & \multirow{3}{*}{$0.039 *$} \\
\hline & Moderate pain & 16 & 50.313 & \pm & 20.700 & & \\
\hline & Severe pain & 10 & 68.400 & \pm & 7.961 & & \\
\hline \multirow{3}{*}{$\begin{array}{l}\text { Post Visual } \\
\text { Reality }\end{array}$} & No pain & 1 & 24.000 & \pm & 0.000 & \multirow{3}{*}{1.455} & \multirow{3}{*}{0.251} \\
\hline & Mild pain & 21 & 30.381 & \pm & 7.984 & & \\
\hline & Moderate pain & 8 & 35.000 & \pm & 7.540 & & \\
\hline \multirow{3}{*}{$\begin{array}{l}\text { Post Guided } \\
\text { Visualization }\end{array}$} & Mild pain & 13 & 33.231 & \pm & 13.953 & \multirow{3}{*}{10.473} & \multirow{3}{*}{$<0.001 *$} \\
\hline & Moderate pain & 13 & 42.308 & \pm & 13.098 & & \\
\hline & Severe pain & 4 & 67.500 & \pm & 9.037 & & \\
\hline
\end{tabular}

*Statistically significant difference at $(P<0.05)$

Table (1): Illustrates socio-demographic characteristics of the studied children. As regards their age, it was found that $60 \%$ of them were between 12 -16 years old with the mean age $(11.933 \pm 2.753)$ years. regarding their sex and educational level, it was clear that $63.33 \%$ of them were females and in primary school.

Table (2): Illustrates percentage distribution of the children's caregivers regarding to their sociodemographic characteristics. It was observed that the age of $53.3 \%$ of them was from $40-60$ years and also $66.67 \%$ of them were female. As regards the caregivers' educational level, it was found that $43.33 \%$ and $23.33 \%$ of them were illiterate and had diploma education respectively. In relation to their occupation, the table presented that $83.33 \%$ of caregivers didn't work because they are mothers and house wives.

Table (3): Demonstrates Percentage distribution of the studied children according to their disease and arterio-venous fistula characteristics. It reveals that the mean \pm SD of disease duration was 5.200 \pm 3.274 years before starting hemodialysis. As regards the duration of their hemodialysis, it ranged from 0.08-8 years. As regards the duration of session it was found that $56.66 \%$ of children had three hours per each session. It was observed that $66.67 \%$ of them had a fistula in their left arm. In relation to the type of fistula, it was found that $83.3 \%$ of children had a brachiocephalic fistula. In addition, the duration of the children's fistula ranged from 0.17-3months with the mean \pm SD was $1.42 \pm 1.015$ years .

Table (4): Illustrates the percent distribution of the studied children's total pain score during AVF cannulation pre and post interventions. It was found that, there was a statistically significant difference among children regarding their Wong Baker faces pain rating scale scores during fistula puncture where $(\mathrm{P}=<0.001, \mathrm{P}=0.022$ and $\mathrm{P}=0.0 .045)$ between preintervention and virtual reality, pre-intervention and guided visualization application and between virtual reality and guided visualization respectively.

Table (5): Reflects the distribution of the studied children according to their mean score of Pain Anxiety level pre and post interventions: virtual reality and guided visualization. It illustrates that there was highly statistically significant difference between pre intervention mean scores of anxiety pain among the studied children compared to post virtual reality application and between pre intervention, post guided visualization application where $(\mathrm{P}=<0.001)$ and means scores were $(57 \pm 18,31 \pm 7.9,41 \pm 16)$ preintervention, post virtual reality and post guided visualization respectively.

Figure (1): Demonstrates that,53.33\% and $33.33 \%$ of the studied children had moderate and severe pain anxiety symptoms pre-intervention respectively while $73.33 \%$ and $46.67 \%$ of them had mild pain anxiety symptoms during virtual reality and guided visualization application respectively.

Table (6): Illustrates relation between the studied children's total pain score and means scores of pain anxiety levels pre and post interventions. It reveals that, there was statistically significant relation between child's pain scores and mean score of the Pain Anxiety Symptom pre-intervention, where $(\mathrm{P}=0.039)$. On the other hand, post visual reality application there was no statistically significant relation between total pain score and means scores of pain anxiety levels where $(\mathrm{P}=0.251)$. Regarding, relation between child's pain scores and mean score of the Pain Anxiety Symptom after guided visualization application, it was noticed that there was statistically significant relation between them, where $(\mathrm{P}=<0.001)$.

\section{Discussion}

Arteriovenous fistula (AVF) cannulation pain may adversely impact the children's quality of life, and it is considered as the primary reason for the failure of them to tolerate dialysis via AVF. So, reducing some 
part of this problem depends on the long- term adaptation of children (Rusch et al 2017). Distraction techniques are the most effective nonpharmacological interventions for mitigating the pain and anxiety experienced by children undergoing needle-related procedures (Bukola \& Paula 2017)

Distraction techniques such as virtual reality and the guided visualization are safer than pharmacological treatments and have fewer or no side effects. Virtual reality control the pain by immersing the child in3dimensional and computer-generated multisensory environment, that offer a non-pharmacological way of pain reduction (Jeffs at al 2014). The guided visualization involves abdominal and diaphragmatic breathing, muscle relaxation and imagining of presence in places such as the seashore, the mountains and the forest in which to imagine natural sounds and smells in mind (Foji et al 2015).

The present study was conducted to evaluate the effect of virtual reality compared to guided visualization on reduction of arteriovenous fistula cannulation pain and pain anxiety level. Results of the present study revealed that two thirds of the studied children aged more than 12 to 16 years old. The apparent incidence of the chronic kidney diseases among adolescents may be attributed to the adoption of unhealthy life style among adolescents and delayed treatment for previous comorbidities, which affect the integrity of the renal system during school age e.g. Frequent post streptococcal glomerulonephritis. This finding is in agreement with (Kaspar et al 2016) who reported in their studies that adolescents have higher incidence rate than other childhood stages. The present study revealed that more than two thirds of the studied children were primary education though their age exceeds the age of primary education. These results cleared the negative impacts of CKD on the child's quality of life particularly the domain related to academic performance as the child may have frequent absenteeism rate and missing school days either because of illness, hospital admission or the frequent dialysis sessions per month. These findings are consistent with (Ahmed A 2018) who mentioned that chronic renal diseases have massive impacts on the children's quality of life.

As regards the site of AVF two thirds of children had a left arm AVF. This result may be due to that left arm is the non-dominant arm and the child always needs to use his or her right hand to perform their daily living activities. Also, the right arm with fistula needs special care, precautions, and exercise. The present study also showed that all of children received three sessions weekly for four hours per session in more than half of them. These results matched with the results of (Elhalafawy 2020) who reported that most of the children undergoing hemodialysis in her study received three dialysis sessions weekly, the duration of each dialysis session was four hours and the majority of children had arteriovenous fistula in their left arm.

One of the non-pharmacological strategies that is used to manage arteriovenous fistula canulation pain and anxiety among children undergoing hemodialysis is virtual reality. It is a distraction method which based on the premise that it requires a large part of conscious attention allowing less brain energy to evaluate and process painful impulses during stressful and painful procedures. The brain receives information about pain sensation from the pain receptors through neural signals. A child's brain requires attention to process this information and there is only a limited amount of information that a brain can attend to process at a specific time (Collins 2019).

Regarding the severity of pain associated with AVF cannulation among the studied children, the present study showed that pain severity decreased from moderate degree in more than half of them pre intervention to mild degree in nearly three quarters of the children post application of virtual reality sessions. The current result may be explained on the basis that virtual reality by overwhelming the brain with input from different senses; it draws heavily on conscious perception, leaving little space for pain sensations to be interpreted. In addition, spending less time concentrating and paying attention to pain contributes to this process. (Wong et al ,2019) supported this current result and stated that virtual reality reduces pain and anxiety experienced by children during venipuncture. On the other hand (Kipping et al.2012) disagreed with the current result as they declared that there weren't any statistically significant changes between virtual reality group and control group in their study.

As regards comparing of the effectiveness of virtual reality versus guided visualization effect on AVF canulation pain, the present study showed that both of the techniques reduced pain during AVF canulation. However guided visualization had lower effect on pain than virtual reality. This can be related to the existence of a visual effect in virtual reality in addition to display images with its headset which makes it easier to attract attention of child, and thus increase its effectiveness. The guided visualization involves only the sound effect, and child should use imagination in order to visualize the environments; if the child's imagination is not strong, the outcome would not be favorable. These findings are in agreement with (Nasirzadeh et al.,2019) who found 
in his study that the guided visualization had lower effect on pain than virtual reality.

Children often perceive hemodialysis session as a period time taken from their lives with a felling of ineluctability and emptiness, generating a negative emotional and cognitive perception of the world (Burrai et al 2019). In addition, Anxiety among those children is common and related to the insertion of needles and the necessary hospital attendance three times weekly for treatment. Therefore alternative, affordable strategies should be used to absorb the children's negative perceptions during hemodialysis and improving the standard of living for them (Saraiva et al 2018).

Results of this present study clarified that guided visualization application resulted in a reduction in mean score of pain anxiety during arteriovenous fistula cannulation among the studied children. This may be attributed to that guided visualization diverts the child attention away from the stressful stimuli. This finding is matched with findings of (Afshar et al.,2018) observed that guided visualization can significantly alleviate anxiety and improve sleep pattern among hemodialysis patients. In addition, (Beizaee et al., 2018) agreed with the current findings as they reported that after the guided imagery application in their study, the anxiety level and depression were significantly lower in the intervention group compared with the control group ( $\mathrm{p}=0.030, \mathrm{p}=0.001$, respectively).

Regarding the effectiveness of guided visualization versus virtual reality on AVF cannulation pain anxiety, the present study revealed that virtual reality was more effective in reducing the severity of pain anxiety than guided visualization among the studied children. This may be due to that most of the children involved in the virtual reality sessions had much enthusiasm to participate actively and welcomed it as a new technology. Moreover, they preferred to use it by themselves so more mental involvement and better diversion of attention from the sources of pain and anxiety was achieved during the AVF cannulation procedure. These findings are congruent with (Opris et al., 2012) who stated that there was an important reduction in the anxiety level in patients during virtual reality implementation in their study.

\section{Conclusion}

According to the findings of the present study, it concluded that both visual reality and guided visualization are effective in reducing arteriovenous fistula canulation pain and pain anxiety for those children undergoing hemodialysis. However, visual reality was more effective technique than guided visualization in reducing AVF cannulation pain and pain anxiety.

\section{Recommendations:}

According to the findings of the present study, the following recommendations are suggested:

1- Visual reality should be used and disseminated to other hemodialysis centers as a strategy to reduce pain and pain anxiety among hemodialysis children with AVF.

2- Implementation of visual reality and guided visualization in care of children with hemodialysis to reduce their arteriovenous fistula puncture pain.

For future nursing researches:

The study's replication using a larger sample from different geographical places, on various age groups, and on other painful procedures to attain more generalization of results.

\section{References:}

- Abdalmajed, A. (2017): Nurses' knowledge and practice Regarding Nursing Care of Hemodialysis Catheter in Pediatric Renal Units in Khartoum State, Published Master Thesis, Faculty of Graduate Studies and Scientific Research, The National Ribat University.

- Afshar M., zadeh A., Gilasi H. \& Gandomani H. (2018): The effects of guided imagery on state and trait anxiety and sleep quality among patients receiving hemodialysis: A randomized controlled trial. Complementary Therapies in Medicine Journals; 40:37-41.

- Ahamed, A. (2018): Effects of empowering families on improving quality of life for children with chronic kidney diseases. American Journal of Nursing Sciences, 7(1), 14-22.

- Alalo, F., Ahmad, A., \& El Sayed, H. (2016): Pain Intensity after an Ice Pack Application Prior to Venipuncture among School-Age Children: An Experimental Study. Journal of Education and Practice, 7(36), 16-25.

- Alhani F., Shad H., Anoosheh M. \& Hajizadeh E. (2010): The Effect of Programmed Distraction on the Pain Caused by Venipuncture among Adolescents on Hemodialysis. Pain Management Nursing, 11, (2) (June): pp 85-91

- Basu, R., Devarajan, P., Wong, H. \& Wheeler, D. (2011): An update and review of acute kidney injury in pediatrics. Pediatric Critical Care Medicine, 12, (3), 339-347.

- Beizaee Y., Rejeh N., Karimooi M., Tadrisi S., Griffiths P. \& Vaismoradi M. (2018): The effect of guided imagery on anxiety, depression and vital signs in patients on hemodialysis. 
Complementary Therapies in Medicine Journal; 33184-190.

- Benjamin, O. \& Lappin, S. (2020): End-stage renal disease. Stat Pearls: online https://www.ncbi.nlm.nih.gov/books/NBK499861

- Bonnie J. \& Stevens D. (2012): Pain assessment and intensity in hospitalized children. Journal of Pain; 13 (9):857-65.

- Bukola I. \& Paula D. (2017): The effectiveness of distraction as procedural pain management technique in pediatric oncology patients: a metaanalysis and systematic review. Journal of Pain Symptom Manag.;54(4):589-600.

- Burrai F., Othman S., Brioni E., Micheluzzi V., Luppi M. \& Apuzzo ( 2019) Effects of Virtual Reality in Patients Undergoing Dialysis: Study Protocol. Holistic nursing practice.;33 (6):327337.

- Celik G., Ozbek O., Yılmaz M., Duman I, Ozbek S. \& Apiliogullari S. (2011): Vapocoolant spray vslidocaine /prilocaine cream for reducing the pain of venipuncture in hemodialysis patients: a randomized, placebocontrolled, Crossover Study, International Journal of Medical Science; 8(7): 623-627.

- CHOC (2020): Children's Guided Imagery for Kids,; Available at WWW.choc.org/programsservices/integrative-health/guided-imagery/, accessed on 18/1/2021

- Collins E. (2019): Effectiveness of Fully Immersive Virtual Reality as Pain and Distress Treatment Method as Compared to Standard Analgesic Treatments in Children Undergoing Painful Medical Procedures: A systemic Review. Master Degree of Science in Child and Family Psychology. University of Canterbury, Christchurch New Zealand.

- Davtalab E., Naji S. \& Shahidi SH. (2016): Comparing the effects of Valsalva maneuver and ice massage at Hoku point methods on pain intensity within the needle insertion to the arteriovenous fistula (AVF) for patients undergoing hemodialysis in the selected hospitals in Isfahan, International Journal of Medical Research \& Health Sciences; 5, 5(S):102

- Donna K. \& Ran D. ( 2012): Distraction Techniques for Children Undergoing Procedures: A Critical Review of Pediatric Research, Journal of Pediatric Nursing; 27(6):652-681

- Elhalafawy S. (2020): Effect of Cryotherapy versus Aromatherapy on Pain of Arteriovenous Fistula Puncture for Children Undergoing Hemodialysis. Published Doctoral Thesis. Faculty of Nursing, Tanta University; 100.
- Foji S., Tadayonfar M. and Mohsenpour M (2015): The study of the effect of guided visualization on pain, anxiety and some other hemodynamic factors in patients undergoing coronary angiography. Complementary Therap Clin Prac; 21:119-23.

- Gong, L., Liu, J., Yan, J. \& Wang L. (2014): Effect of puncture-related pain on the quality of life in patients undergoing maintenance hemodialysis through internal arteriovenous fistula. Zhong nan da xue xue bao. Yi xue ban= Journal of Central South University. Medical Sciences, 39(12), 1292-1298.

- Hassan, A., Darwish, M., El-Samman, G. \& Fadel F. (2013): The impact of cryotherapy on pain intensity at puncture sites of arteriovenous fistula among children undergoing hemodialysis, Unpublished PHD thesis of pediatric nursing, faculty of nursing, Cairo University.

- Ibrahim, O. \& Abd El-Gawad S. (2017): Fostering safe vascular access for adolescents during hemodialysis using cushion cannulation versus common cannulation techniques, Journal of Nursing Education and Practice; 7 (7): 2.

- Jeffs. D., Dorman. D., Brown S., Files A., Graves T., Kirk E. \& Swearingen C. (2014): Effect of virtual reality on adolescent pain during burn wound craw. Journal of burn care and research 35(5), 395-408.

- Kaspar, C., Bholah R. \& Bunchman T. (2016): A review of pediatric chronic kidney disease. Blood Purification Journal; 41(1):211-7.

- Kipping, B., Rodger, S., Miller K. \& Kimble, R. (2012): Virtual reality for acute pain reduction in adolescents undergoing burn wound care: A prospective randomized controlled trial. Burns, 38 (5); 650-657.

- Masalskienė, J., Rudaitis, Š., Vitkevič, R., Čerkauskienè, R., Dobilienè, D., \& Jankauskienè, A. (2021). Epidemiology of chronic kidney disease in children: a report from Lithuania. Medicina, 57(2), 112.

- McCracken, L., \& Dhingra, L. (2002): A short version of the Pain Anxiety Symptoms Scale (PASS-20): preliminary development and validity. Pain Res Manag;7(1):45-50.

- Mitchell C. (2020): Virtual Reality; Available at www.investopedia.com/terms/v/virtualreality.asp, accessed on 19/1/2021

- Moosazadeh, M., Nesami, M \& Goudarzian, A (2020): Effect of cryotherapy on arteriovenous fistula puncture-related pain in hemodialysis patients: A systematic review and metaanalysis. Complementary therapies in medicine, 49, 102326.. 
- Nasirzadeh, A., Mircheraghi S., Ghodrati M. \& Shareinia H (2019): Comparing the Effect of Guided Visualization and Virtual Reality Techniques on Cannulation Pain in Hemodialysis Patient. Journal of Research in Medical and Dental Science.; 7(3):55-62.

- Obiagwu, P., Sangweni, B., Moonsamy, G. \& Khumalo., T. (2018): Health-related quality of life in children and adolescents with end-stage renal disease receiving dialysis in Johannesburg, SAJCHJUNE 2018; 12 (2):58-62.

- Onder, A., Flynn, J., Billings, A., Deng, F., DeFreitas, M., Katsoufis \& Wood, E. (2020): Predictors of time to first cannulation for arteriovenous fistula in pediatric hemodialysis patients: Midwest Pediatric Nephrology Consortium study. Pediatric Nephrology, 35(2), 287-295.

- Opris, D., Pintea, S., Garcia-Palacios., A., Botella, C., Szamoskozi, S. \& David D. (2012): Virtual reality exposure therapy in anxiety disorders: A quantitative meta-analysis. Depression and Anxiety;29(2): 85-93

- Othman, A., Buang, M., Taib, M., Mohamad, N. \& Nasir A. (2013): Guided imagery and relaxation audio for children with cancer: Development and evaluation.

- Rüsch, D., Koch T. \& Spies M. (2017): Pain during venous cannulation. Deutsches Ärzteblatt International; 114 (37): 605-11.

- Saraiva M., Richards M. \& Fortnum D. (2018): The Profile of Nephrology Nursing, 1st edition, chapter 2 European Dialysis and Transplant Nurses Association / European Renal Care Association (EDTNA/ERCA), Germany.

- Tomasello, C., Pinto, R., Mennini, C., Conicella, E., Stoppa, F. \& Raucci U (2018): Scrambler therapy efficacy and safety for neuropathic pain correlated with chemotherapyinduced peripheral neuropathy in adolescents: A preliminary study. Pediatric blood \& cancer, 65(7), e27064.

- Vaidya, S. \& Aeddula, N. (2020): Chronic renal failure. StatPearls online: https://www.ncbi.nlm.nih.gov/books/NBK535404 /.

- Wong, C., Lui, M. \& Choi, K. (2019): Effects of immersive virtual reality intervention on pain and anxiety among pediatric patients undergoing venipuncture: a study protocol for a randomized controlled trial. Trials, 20(1), 1-10.

- Wong, D. \& Baker, C. (1988): Pain in children: comparison of assessment scales. Pediatric Nursing 14(1), 9-17.
- Yalda R., Mohaddeseh G., Sahar R., Anoush A., Mohammad E. \& Alireza G. (2020): Analgesia for pediatric arteriovenous fistula cannulation in hemodialytic patients: A comparison of lidocaine gel, lidocaine spray, and needle plate; Available at www.indianjnephrol.org/preprintarticle.asp, accessed on $16 / 1 / 2021$ 